\title{
Development and research of pole-changing winding for a close pole ratio
}

\author{
Daulet Rismukhamedov, Maxsud Bobojanov, Furkat Tuychiev, Khusniddin Shamsutdinov ${ }^{*}$ \\ Tashkent State Technical University named after Islam Karimov, Tashkent, Uzbekistan
}

\begin{abstract}
The article presents a methodology for developing poleswitched windings with a pole pair ratio of $5 / 6$ with 108 stator slots, the results of the analysis and ways to improve the electromagnetic properties, and also the areas of application of the obtained windings are determined.
\end{abstract}

\section{Introduction}

The development of pole-changing winding circuits for a close pole ratio is an urgent task due to the widespread prevalence of two-speed electric machines with a close speed ratio. First of all, this includes mechanisms with a fan type of load or the so-called turbine mechanisms (pumps, fans, blowers, etc.) $[1,7]$.

Also, such windings can be used in two-speed asynchronous generators for wind turbines. These windings must be high-tech, have a minimum number of leads and switching contacts (it is better not to have them at all), as well as have improved electromagnetic properties so that their use on the stator of a two-speed electric machine makes it possible to bring them closer in weight, size and electromagnetic parameters to conventional electric machines normal execution $[2,5]$.

One of the most common speed ratios in two-speed motors used on fan-driven drives is the 5:6 ratio.

In this case, the first speed of $600 \mathrm{rpm}$ is the main one, at which the electric machine will operate if the mechanism is fully loaded, and the second speed $(500 \mathrm{rpm})$ is auxiliary and is used, as mentioned above, to regulate productivity, for rational use of electricity and natural resources in underload modes, and can also serve as the first stage in a step start.

Many of the developed pole-changing winding with a close pole ratio do not find practical application due to a large number of lead ends, switching contacts, deteriorated electromagnetic properties, and the complex manufacturing technology associated with the implementation of coils with multi-turn and different steps [3-8].

Creating a two-speed motor, approaching in its power and weight and size to conventional single-speed machines, makes it possible to improve the existing electric drive with and replace some single-speed motors to save energy and natural resources in little loaded modes, as well as to facilitate the start-up process, powerful engines $[4,9,10]$.

Based on the method "Discretely - specified spatial functions" (DSSF), many polechanging winding schemes have been developed for a wide range of pole-to-phase ratios, which are close in properties to the windings of serial single-speed motors $[13,14]$.

* Corresponding author: shamsutdinov_husniddin@bk.ru 


\section{Materials and Methods}

\subsection{Experimental study of power quality}

Consider the construction pole- changing winding on the most current ratio poles $5 / 6$, placed in 108 stator slots.

For the original windings, we take two two-layer looped $\mathrm{m}$-zone stator windings placed in 108 slots, with the numbers of poles $\mathrm{p}_{1}=5$ and $\mathrm{p}_{2}=6$, and for $\mathrm{p}_{1}=5$, a winding with a fractional number of slots per pole and phase $q_{1}=7 \frac{1}{5}$ and for $2 \mathrm{p}_{2}=6$ winding with a number of slots per pole and phase $\mathrm{q}_{2}=6$ increments $\mathrm{y}_{1}=1$ to 12 and $\mathrm{y}_{2}=1-10$, respectively.

By placing the bottom row of the DSSF of each winding under each other (Table 1), according to the state of the name of the phase in the groove, you can get the resulting combination of the two windings. Analyzing the phase conjugation, you can see that each phase of one pole is in contact with all phases of the second pole, i.e. according to the phase conjugation tables for this winding, the switching scheme "three three-phase stars" is suitable $[11,12,15]$.

By the name of the phase in the groove with one and the other windings, you can determine the branch to which this or that coils number corresponds.

Table 1. Placement of windings in the stator slots

\begin{tabular}{|c|c|c|c|c|c|c|c|c|c|c|c|c|c|c|c|c|c|c|c|c|c|c|c|c|c|c|c|}
\hline \multicolumn{27}{|c|}{ Stator slots } & \multirow{2}{*}{$\frac{0}{0}$} \\
\hline- & 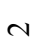 & $m$ & $\nabla$ & in & 0 & $r$ & $\infty$ & a & $\stackrel{0}{\circ}$ & $=$ & $\approx$ & 2 & \pm & $=$ & 0 & I & $\infty$ & 2 & సి & $\bar{N}$ & ป & $\tilde{\vartheta}$ & $\stackrel{\unlhd}{\sim}$ & 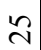 & $\underset{\sim}{2}$ & $\hat{\imath}$ & \\
\hline$\underline{\mathrm{a}}$ & $\mathrm{a}$ & $\mathrm{a}$ & $\mathrm{a}$ & $\mathrm{a}$ & $\mathrm{a}$ & $\underline{\mathrm{a}}$ & $\mathrm{a}$ & $\mathrm{b}$ & b & $\mathrm{b}$ & b & $\underline{\underline{v}}$ & b & b & c & $\mathrm{c}$ & c & $\underline{\mathrm{c}}$ & $\mathrm{c}$ & $\mathrm{c}$ & c & $\mathrm{a}$ & $\mathrm{a}$ & $\underline{\mathrm{a}}$ & $\mathrm{a}$ & $\mathrm{a}$ & $\mathrm{p}_{1}=5$ \\
\hline $\mathrm{d}$ & $\mathrm{d}$ & $\mathrm{d}$ & $\mathrm{d}$ & $\mathrm{d}$ & $\mathrm{d}$ & e & $\mathrm{e}$ & $\mathrm{e}$ & $\mathrm{e}$ & $\mathrm{e}$ & $\mathrm{e}$ & f & $\mathrm{f}$ & $f$ & $\mathrm{f}$ & f & $\mathrm{f}$ & $\mathrm{d}$ & $\mathrm{d}$ & $\mathrm{d}$ & $\mathrm{d}$ & $\mathrm{d}$ & $\mathrm{d}$ & $\mathrm{e}$ & $\mathrm{e}$ & $\mathrm{e}$ & $\mathrm{p}_{2}=6$ \\
\hline
\end{tabular}

\begin{tabular}{|c|c|c|c|c|c|c|c|c|c|c|c|c|c|c|c|c|c|c|c|c|c|c|c|c|c|c|}
\hline \multicolumn{26}{|c|}{ Stator slots } & \multirow{2}{*}{$\frac{0}{0}$} \\
\hline$\infty$ & సે & ల & $\bar{m}$ & m) & $m$ & $\dot{m}$ & $m$ & 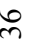 & 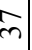 & $\infty$ & s. & $\bar{F}$ & テ & $\mathscr{F}$ & 寸 & $g$ & + & f & $\stackrel{\infty}{+}$ & $g$ & in & $\bar{n}$ & ñ & $\hat{n}$ & 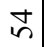 & \\
\hline $\mathrm{a}$ & $\mathrm{a}$ & $\mathrm{b}$ & $\underline{b}$ & $\mathrm{~b}$ & $\mathrm{~b}$ & $\mathrm{~b}$ & b & $\mathrm{b}$ & $\underline{\mathrm{c}}$ & 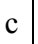 & $\mathrm{c}$ & c & $\mathrm{c}$ & $\underline{\mathrm{c}}$ & $\mathrm{c}$ & $\mathrm{a}$ & $\mathrm{a}$ & $\mathrm{a}$ & $\mathrm{a}$ & $\underline{\mathrm{a}}$ & $\mathrm{a}$ & $\mathrm{a}$ & $\mathrm{b}$ & $\mathrm{b}$ & $\mathrm{b}$ & $\mathrm{p}_{1}=5$ \\
\hline $\mathrm{e}$ & \begin{tabular}{l|l}
$\mathrm{e}$ & $\mathrm{c}$
\end{tabular} & $\mathrm{e}$ & $f$ & $\mathrm{f}$ & $\mathrm{f}$ & $\mathrm{f}$ & $f$ & $\mathrm{f}$ & $\mathrm{d}$ & $\mathrm{d}$ & $\mathrm{d}$ & c & $\mathrm{d}$ & e & e & $\mathrm{e}$ & $\mathrm{e}$ & $\mathrm{e}$ & $\mathrm{e}$ & $\mathrm{f}$ & $f$ & $\mathrm{f}$ & $\mathrm{f}$ & $\mathrm{f}$ & $f$ & $\mathrm{p}_{2}=6$ \\
\hline
\end{tabular}

\begin{tabular}{|c|c|c|c|c|c|c|c|c|c|c|c|c|c|c|c|c|c|c|c|c|c|c|c|c|c|c|c|}
\hline \multicolumn{27}{|c|}{ Stator slots } & \multirow{2}{*}{$\frac{0}{0}$} \\
\hline in & in & in & $\stackrel{\infty}{n}$ & in & 8 & 5 & $\widetilde{\sigma}$ & 6 & ț & 6 & ㄴ. & $\hat{6}$ & $\infty$ & के & $?$ & $\pi$ & $\frac{1}{2}$ & $m$ & 过 & 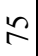 & 2 & $\approx$ & $\stackrel{\infty}{\sim}$ & 2 & $\infty$ & $\infty$ & \\
\hline$\underline{b}$ & $\mathrm{~b}$ & $\mathrm{~b}$ & $\mathrm{~b}$ & $\mathrm{c}$ & $\mathrm{c}$ & $\underline{\mathrm{c}}$ & $\mathrm{c}$ & $\mathrm{c}$ & c & $\mathrm{c}$ & $\mathrm{a}$ & $\underline{\mathrm{a}}$ & $\mathrm{a}$ & $\mathrm{a}$ & $\mathrm{a}$ & $\mathrm{a}$ & $\mathrm{a}$ & $\underline{\mathrm{b}}$ & b & $\mathrm{b}$ & $\mathrm{b}$ & $\mathrm{b}$ & $\mathrm{b}$ & $\underline{b}$ & $\mathrm{~b}$ & $\mathrm{c}$ & $\mathrm{p}_{1}=5$ \\
\hline$d$ & $\mathrm{~d}$ & $d$ & $\mathrm{~d}$ & $\mathrm{~d}$ & $d$ & $\mathrm{e}$ & $\mathrm{e}$ & $\mathrm{e}$ & $\mathrm{e}$ & $\mathrm{e}$ & $\mathrm{e}$ & $\mathrm{f}$ & $\mathrm{f}$ & $\mathrm{f}$ & $\mathrm{f}$ & $\mathrm{f}$ & $\mathrm{f}$ & $\mathrm{d}$ & $\mathrm{d}$ & $\mathrm{d}$ & d & $\mathrm{d}$ & $\mathrm{d}$ & $\mathrm{e}$ & $\mathrm{e}$ & $\mathrm{e}$ & $\mathrm{p}_{2}=6$ \\
\hline
\end{tabular}

\begin{tabular}{|c|c|c|c|c|c|c|c|c|c|c|c|c|c|c|c|c|c|c|c|c|c|c|c|c|c|c|c|}
\hline \multicolumn{27}{|c|}{ Stator slots } & \multirow{2}{*}{$\frac{0}{0}$} \\
\hline$\infty$ & $\infty$ & $\infty$ & $\infty$ & $\infty$ & $\infty$ & $\infty$ & $\infty$ & ㅇ & $\bar{a}$ & ส & 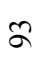 & ず & $\approx$ & \% & $\hat{a}$ & $\stackrel{\infty}{a}$ & ৪ & & 응 & 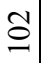 & $\tilde{0}$ & $\stackrel{\Xi}{ }$ & $\stackrel{n}{0}$ & $\stackrel{0}{\circ}$ & $\hat{0}$ & $\stackrel{\infty}{0}$ & \\
\hline c & $\mathrm{c}$ & $\mathrm{c}$ & $\underline{\mathrm{c}}$ & $\mathrm{c}$ & $\mathrm{c}$ & $\mathrm{a}$ & $\mathrm{a}$ & $\mathrm{a}$ & $\underline{\mathrm{a}}$ & $\mathrm{a}$ & a & $\mathrm{a}$ & $\mathrm{b}$ & $b$ & $\underline{\mathrm{b}}$ & $\mathrm{b}$ & $b$ & $b$ & $\mathrm{~b}$ & c & $\underline{\mathrm{c}}$ & c & $\mathrm{c}$ & $\mathrm{c}$ & c & c & $\mathrm{p}_{1}=5$ \\
\hline $\mathrm{e}$ & $\mathrm{e}$ & $\mathrm{e}$ & f & $\mathrm{f}$ & $\mathrm{f}$ & $\mathrm{f}$ & $\mathrm{f}$ & $\mathrm{f}$ & $d$ & $d$ & $\mathrm{~d}$ & d & $\mathrm{d}$ & $d$ & $\mathrm{e}$ & $\mathrm{e}$ & $\mathrm{e}$ & $\mathrm{e}$ & $\mathrm{e}$ & $\mathrm{e}$ & $\mathrm{f}$ & $\mathrm{f}$ & $\mathrm{f}$ & $f$ & $\mathrm{f}$ & $f$ & $\mathrm{p}_{2}=6$ \\
\hline
\end{tabular}


Combining groups of coils into a winding is carried out following the connections of the coils in the BS "YYY / YYY". Moreover, the groove No. 1 from the side $p_{l}=5$ pole winding corresponds to phase $A$, and from the side $p_{2}=6$ to phase $D$, therefore, belongs to the branch D -A. Based on this method, we group the coils ( Table 2 ) in the BS branch.

Table 2. Distribution of coils in the branches of the basic circuit

\begin{tabular}{|c|c|c|c|c|c|c|c|c|c|}
\hline \multirow[b]{3}{*}{ 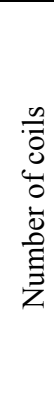 } & \multicolumn{9}{|c|}{ BS branches YYY / YYY } \\
\hline & D-A & D-B & $\mathrm{D}-\mathrm{C}$ & E-A & E-B & $\mathrm{E}-\mathrm{C}$ & F-A & F-B & $\mathrm{F}-\mathrm{C}$ \\
\hline & 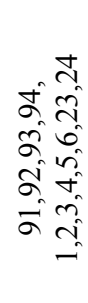 & 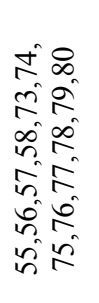 & 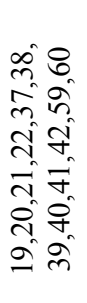 & 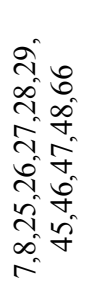 & 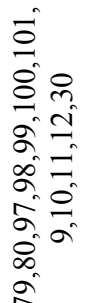 & 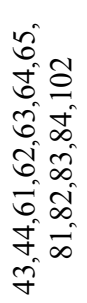 & 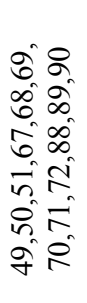 & 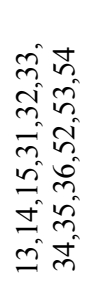 & 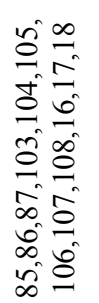 \\
\hline
\end{tabular}

\section{Results and Discussion}

The resulting pole-changing winding is symmetrical concerning the power source from the $2 \mathrm{p}_{1}$ side, and from the $2 \mathrm{p}_{2}$ side, it has a discrepancy between the total EMF vectors (Figure 1.11) between the branches of the same phase DA and D-B in amplitude by $1.1 \%$, and in phase by 10.2 electrical degrees and, accordingly, this leads to a difference in the winding coefficients (tables 3, 4)

Table 3. Distribution of coils in the branches of the basic circuit

\begin{tabular}{|c|c|c|c|c|c|c|c|c|c|}
\hline & \multicolumn{10}{|c|}{ BS branches YYY / YYY } \\
\cline { 2 - 11 } & A-D & B-D & C-D & A-E & B-E & C-E & A-F & B-F & C-F \\
\hline A & 19.79 & 19.58 & 19.99 & 19.79 & 19.58 & 19.99 & 19.79 & 19.58 & 19.99 \\
\hline $\mathrm{k}_{\mathrm{wk}}$ & 0.824 & 0.816 & 0.833 & 0.824 & 0.816 & 0.833 & 0.824 & 0.816 & 0.833 \\
\hline$\varphi$ & 44.91 & 55.08 & 55.0 & 164.91 & 175.08 & 175.0 & 75.09 & 64.92 & 65 \\
\hline
\end{tabular}

Table 4. Distribution of coils in the branches of the basic circuit

\begin{tabular}{|c|c|c|c|c|c|c|c|c|c|}
\hline & \multicolumn{10}{|c|}{ Branches БC YY/YYY } \\
\cline { 2 - 11 } & D-A & E-A & F-A & D-B & E-B & F-B & D-C & E-C & F-C \\
\hline $\mathrm{A}$ & 19.65 & 19.65 & 19.65 & 19.65 & 19.65 & 19.65 & 19.65 & 19.65 & 19.65 \\
\hline $\mathrm{k}_{\mathrm{wk}}$ & 0.819 & 0.819 & 0.819 & 0.819 & 0.819 & 0.819 & 0.819 & 0.819 & 0.819 \\
\hline$\varphi$ & 60 & 60 & 60 & 180 & 180 & 180 & 60 & 60 & 60 \\
\hline
\end{tabular}

Analysis of the harmonic composition of the MDS patterns showed that higher harmonic ones are present on the side of both poles, but their amplitude, taking into account the winding coefficients, decreases and does not significantly affect the operation of the engine and from the side $2 \mathrm{p}_{1}=10$ poles relative to the first harmonic, the amplitude of the highest $\mathrm{x}$ harmonically $\mathrm{x}$ equal to $\mathrm{A}_{2}=0.64 \%$, $\mathrm{A}_{5}=0.75 \%, \mathrm{~A}_{6}=0.42 \%, \mathrm{~A}_{7}=0.59 \%$, and from the side $2 \mathrm{p}_{2}=12$ poles $\mathrm{A}_{2}=$ $1.28 \%, \mathrm{~A}_{5}=0.77 \%, \mathrm{~A}_{7}=0.37 \%$.

The differential scattering coefficient $\sigma_{0}$ (in the air gap) is one of the criteria for evaluating the winding properties, namely, an indicator of the ratio of the reactance of the highest harmonic to the main reactance of the winding. The calculation of differential scattering 
coefficient is carried out based on the Krondl theorem using the polygon of magnetizing forces Gerges [10, 16].

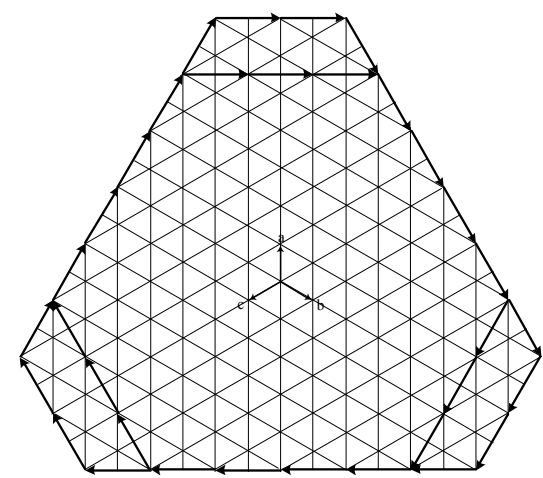

a)

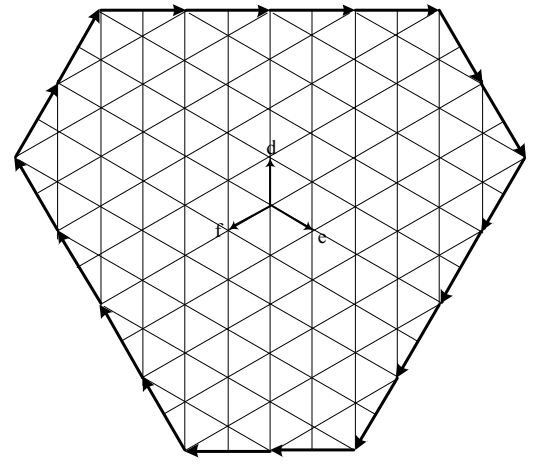

b)

Fig. 1. Gerges diagram a) for $\mathrm{p}_{1}=5, \mathrm{~b}$ ) for $\mathrm{p}_{2}=6$

In figure 1 are diagrams Gerges for pole-changing winding based on BS «YYY / YYY» poles on the ratio 5/6 in 108 stator slots with the winding step, $y=10$.

The values of the coefficients of differential scattering on the side $\mathrm{p}_{1}=5$ is $\sigma_{0}=15.3 \%$, and on the side $\mathrm{p}_{2}=6-\sigma_{0}=2.2 \%$.

The matching of the magnetic inductions in the air gap can be achieved only due to a small difference in the values of the winding coefficients, and from $2 p 1$ and $2 p 2$ of the pole side, respectively, $\mathrm{k}_{\mathrm{wk} 1}=0.833$ and $\mathrm{k}_{\mathrm{wk} 2}=0.831$.

Air-gap magnetic induction ratio:

$$
\frac{B_{2}}{B_{1}}=\frac{p_{2} k_{\mathrm{obm} 1} w_{1}}{p_{1} k_{\mathrm{obm} 2} w_{2}}=\frac{6 \cdot 0.833 \cdot 6}{5 \cdot 0.831 \cdot 6}=1.2
$$

As can be seen from the above analysis, along with the asymmetry in this winding, the magnetic inductions in the air gap are not matched, which leads to underutilization of the active part of the machine at the highest rotation speed. By rum addition, not evenly distributed the picture from MDS 2 p $1=10$ results in the appearance of the engine noise and vibration.

To improve the electromagnetic properties and ensure high utilization of the active part of the machine on the high-speed side (especially for motors of mechanisms with a fan load), it is advisable to use windings according to the "YYY / YYY scheme with additional branches", they are also very convenient in operation since there is no additional switching device $[2,16]$.

Based on the data from the previous example (Table 1), let's build polechanging winding according to the "YYY / YYY with additional branches" scheme.

To do this, we exclude one coil from each phase of the pole zone from the side of the pole $2 p_{1}$. Accordingly, from the side of the pole $2 p_{2}$, these can be coils in the grooves under the numbers: for phase D - 12, 30, 48; for phase E - 6, 24, 42; for phase F - 18, 36, 54 (in Table 1 they are underlined below). These coils are output to additional branches and, redistributing in phases, participate in creating a magnetic field of polarity $2 p_{2}$. In this case, the mutual compensation of the EMF of the additional branches is carried out when the coils of the additional branches are connected in series and distributed along the circumference of the magnetic circuit with a lag in relation to each other by a shift angle 
equal to 120 electrical degrees when the winding is placed in a magnetic field with a smaller number of poles [17].

The combination of groups of coils into a winding is carried out in accordance with the method of the previous example with the connections of the coils in the BS " YYY / YYY with additional branches ".

The analysis of the harmonic composition of the MDS patterns showed that higher harmonic ones are present on the side of both poles. Still, their amplitude, taking into account the winding coefficients, decreases and does not significantly affect the operation of the engine. From the side $2 \mathrm{p} 1=10$ poles relative to the first harmonic, the amplitude of the higher harmonic is equal to A $2=1.08 \%$, A $3=1.37 \%$, A $5=0.72 \%$, A $6=0.39 \%$, A $7=0.38 \%$, and from the side $2 \mathrm{p}_{2}=12$ poles A $2=1.29 \%$, A $5=1.22 \%$, A $7=0.37 \%$.

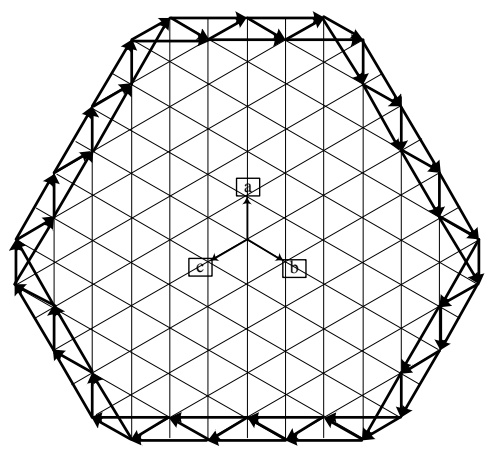

a)

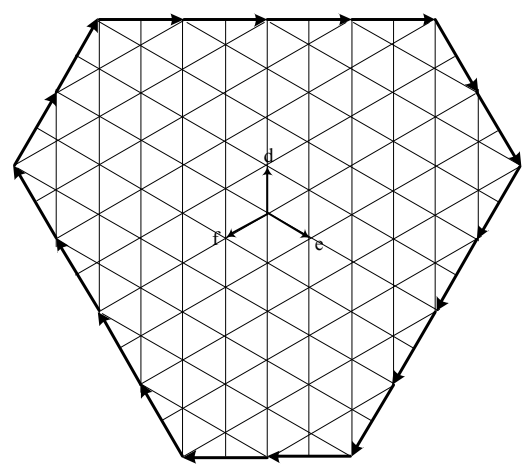

b)

Fig. 2. Gerges diagram «YY Y / YYY with additional branches "a) for $\mathrm{p}_{1}=5, \mathrm{~b}$ ) for $\mathrm{p}_{2}=6$

In figure 3 are diagrams Gerges for pole-changing winding based on BS «YYY / YYY with additional branches" at ratio poles 5 / 6 in 108 stator slots with the winding step, $\mathrm{y}=$ 5 . The values of the differential scattering coefficients with side $2 p_{1}=10 \quad \sigma_{0}=2.1 \%$, and with side $2 \mathrm{p}_{1}=12-\sigma_{0}=2.2 \%$ [2].

$$
\frac{B_{2}}{B_{1}}=\frac{p_{2} k_{\mathrm{obm} 1} w_{1}}{p_{1} k_{\mathrm{obm} 2} w_{2}}=\frac{6 \cdot 0.833 \cdot 5}{5 \cdot 0.827 \cdot 6}=1.01
$$

It is advisable to make the additional branches with a wire with a cross-section three times larger (in these coils, the current flows three times as much) and, accordingly, with the number of turns three times less than in the other coils. In this case, almost complete matching of magnetic inductions in the air gap will be achieved, at which the ratio of magnetic inductions should be as close to unity as possible:

$$
\frac{B_{2}}{B_{1}}=\frac{p_{2} k_{\mathrm{obm} 1} w_{1}}{p_{1} k_{\mathrm{obm} 2} w_{2}}=\frac{6 \cdot 0.833 \cdot 5}{5 \cdot 0.827 \cdot 6}=1.01
$$

\section{Conclusion}

The resulting winding and motor are used in fan mechanisms and are loaded, since the power and torque of the motor increase in inverse proportion to the number of poles.

Thus designed pole-changing winding IME $\mathrm{w} r$ improved picture MDS and uniformly distributed on the circle diagram Gerges, that lead to a decrease in the presence of higher 
harmonics and decrease of the differential scattering coefficients as well as to improve the vibroacoustic characteristics from both the pole.

\section{References}

1. Kovacs C 2018 Pole-Changing Windings for Close Ratio and 1:N Ratio Using the 3//Y/3//Y method. Advances in Science, Technology and Engineering Systems Journal 3 (4) pp 241-253. DOI: 10.25046/aj030424.

2. Kh.G. Karimov. Methods for developing pole-changing windings for motors in controlled electrical drives in general use. Problemi Informatiki i Energetiki, 1, (1993)

3. M. V. Cistelecan, L. M. Melcescu, H. B. Cosan and M. Popescu, "Induction motors with changeable pole windings in the ratio 1:4" International Aegean Conference on Electrical Machines and Power Electronics and Electromotion, Joint Conference, Istanbul, 2011, pp. 781-786, doi: 10.1109/ACEMP.2011.6490700.

4. Karimov Kh.G., Tupoguz A. Method for Designing Electrically Aligned Windings in AC Machines. Electricity 1987, № 9, pp. 29-38.

5. Makhsud Bobojanov, Dauletbek Rismuxamedov, Furkat Tuychiev, Khusniddin Shamsutdinov, Khayotullo Magdiev. "Pole-changing motor for lift installation". E3S Web of Conferences 216, 01164 (2020).

6. Bobojanov M.K., Eshmurodov Z.O., Ismoilov M.T., "Research of Dynamic Properties of Electric Drives of Mining Complexes" International Journal of Advanced Research in Science Engineering and Technology. IJARSET, Volume 6, Issue 5 May. India. pp.9200-9207, (2019)

7. Kh.G. Karimov, M.K.Bobojanov. "New pole-changing windings of asynchronous motors". Magazine "Elektrichestvo" (Russia), 1996, №1, Moscow, pp. 27-32

8. Kh.G. Karimov and M.K.Bobojanov, "New design of pole-changing windings for induction Motors for intense operating conditions", Magazine "Electrical Technology" (United Kingdom), №1, 1996, pp.19-28.

9. M.K.Bobojanov, E. Bolte. Polumschaltbare Motoren: neue Perspektiven. "UNIFORSCHUNG" Forschungsmagazin der Universitaet der Bundeswehr Hamburg. 12.Jahrgang.2002. Seite 2-7.

10. D. Rismuhamedov, F. Tuychiev, S. Rismuhamedov, "Pole-changing windings for turbomechanism engines" IOP Conference Series: Materials Science and Engineering 883 (2020) 012140. Doi: 10.1088/1757-899X/883/1/012140.

11. Bobojanov M.K., Rismukhamedov D.A., Tuychiev F.N., Shamsutdinov H.F. and Magdiev H.G. (2020). Construction and analysis of the pole-changing windings for the pole pairs ratio $5 / 6$ by method discretely specified spatial function. International Journal of Advanced Science and Technology, 29(7), 9206-9211.

12. Kh.G.Karimov and M.K. Bobojanov, "Two speed induction motors with an improved design of pole- changing windings". Electromotion'99. 3rd International Symposium on advanced Electromechanical Motion Systems; Patras, Greese, July 8-9, 1999, pp.35-38.

13. M.K. Bobojanov, M. Sadikova, H. Hakan: "New pole-changing asynchronous generator for wind devices", PEOCO 2007-First Power Ingeneering and Optimization Conference, Malaysia, June 6, 2007.

14. Kh.G. Karimov, D.A. Rismukhamedov: "Two - speeds induction motors for the energy saving measures", 6 th International conference on Engineering of Modern Elec-tric Systems.- Oradea (Romania), pp. 385-389, 2001.

15. Kh.G. Karimov, M.K. Bobojanov, D.A. Rismuhamedov: "The methodology of construction and analysis of the electromagnetic properties of a pole switchable wind-ing", Bulletin of TSTU, no. 3, pp. 71-78, 2004. 
16. H. Liu, J. Wang, Z. Zhang: "Performance analysis of variable speed multiphase induction motor with pole phase modulation", Archives of electrical engineering, vol. 65 (3), pp. 425-436 (2016).

17. M.K. Bobojanov, D.A. Rismukhamedov, F.N. Tuychiev: "Development of a polechanging winding for a 5/6 pole ratio at 108 stator slot using the DSSF method with additional branches". Bulletin of TSTU, No. 1 (106), pp. 57-63, 2019. 